\title{
Editor's Introduction: Terrorism and Violent Extremism
}

\author{
Gary LaFree $^{1} \cdot$ Frank Weerman $^{2} \cdot$ Catrien Bijleveld $^{2}$ \\ Published online: 9 September 2020 \\ (c) Springer Science+Business Media, LLC, part of Springer Nature 2020
}

In 2012 the Journal of Quantitative Criminology released a previous special volume on "Quantitative Approaches to the Study of Terrorism." The contributions to this issue highlighted the methodological and statistical innovations that were taking place in the area of criminology-oriented terrorism studies. In their introduction (LaFree and Freilich 2012), the editors of this special issue pointed out that until then very few empirical studies of terrorism relied on inferential statistics or testing hypotheses with appropriate controls and accepted statistical methods. However, the editors also concluded (p. 5) that "the situation with regard to quantitative approaches to the study of terrorism has begun to rapidly change."

These changes have accelerated in the eight years since the earlier special issue was published. This is illustrated by a recent overview of Schuurman (2020), who examined articles published between 2007 and 2016 in nine leading journals on terrorism. Based on a sample of nearly 3500 articles, he concludes that the use of primary data and more sophisticated data collection and analytic methods have become far more common during this period. However, he also notes that there is still much room for improvement and that a minority of all published papers employ inferential statistics. Schuurman also points out that many scholars continue to work alone and that most authors are one-time contributors.

In the introduction to the 2012 special issue, the editors also explained that one of the main drivers for improving empirical work in the study of terrorism had been expanded funding opportunities, especially from the U.S. Department of Homeland Security, the National Institute of Justice and the National Science Foundation. However, in the last eight years, these U.S. funding agencies have been joined by research funds coming from other parts of the world. The most notable example is the European Union research funding program, previously called FP7 and more recently Horizon 2020 (see https://ec.europa.eu/ programmes/horizon2020/en). The EU program includes various calls that are focused on or relevant to the study of radicalization, violent extremism and terrorism. It has already resulted in a substantial number of funded collaboration efforts, notably a recent project

Gary LaFree

glafree@umd.edu

Frank Weerman

FWeerman@nscr.nl

Catrien Bijleveld

CBijleveld@nscr.nl

1 University of Maryland, College Park, MD, USA

2 NSCR, Amsterdam, Netherlands 
called Processes Leading to Organised Crime and Terrorist Networks (PROTON 2020). Over a three-year period, this ambitious project has brought together an international consortium of 21 partners from 10 European countries as well as from Israel, Switzerland and the United States. PROTON researchers conducted various empirical field studies and a meta-analysis, and developed agent-based modelling simulations of the effects of different societal and environmental changes on terrorism. The first article of this special issue (Wolfowicz et al. 2019) was a product of the PROTON project, as were two more of the contributions to this special issue (by LaFree et al. 2019 and Hasisi et al. 2019a). Another contribution (Perry 2019) was a product of an earlier initiative funded by the European Union called PRIME (2015).

The underlying reality of radicalization, violent extremism and terrorism has also continued to evolve over the past eight years since the earlier volume. Driven especially by the deadly rise of the Islamic State and its allies, world-wide terrorism rates reported in the Global Terrorism Database (GTD) soared from around 5000 attacks in 2011 to more than 17,000 in 2014 (LaFree and Dugan 2016). However, after reaching a peak in 2014, worldwide terrorism rates from GTD have now declined for five straight years (LaFree 2019). From the high mark in 2014, the total attacks reported by the GTD in 2019 had decreased to just under 8500 , and the total number of deaths had dropped from 44,000 to just over 20,000 (Miller 2020). Much of the drop in attacks and fatalities was due to declining activity by the Islamic State (IS) in Iraq (Miller 2020). However, at the same time the global reach of IS and its affiliates continued to expand geographically (notably to various countries in Africa) so that by 2019 a total of 57 countries had experienced IS-related terrorist attacks (Miller 2020). And within the same period, we witnessed a rise in often deadly terrorist violence by groups like Boko Haram in the Sahel.

The period between the publication of the two special issues also witnessed major increases in right-wing extremist violence. For example, deadly attacks targeting Hispanic Americans in the United States and Muslims in New Zealand in 2019 marked a sharp increase in the lethality of racially and ethnically motivated terrorist attacks, many of which were motivated by white supremacy, xenophobia, and anti-immigrant beliefs. At least 86 people were killed in such attacks in Australasia, North America, and Western Europe in 2019, compared to 52 in 2018.

Concerns about terrorism do not seem to have greatly diminished since the publication of the earlier special issue. A national survey by the Pew Research Center (Bialik 2018) found that Americans ranked addressing terrorism concerns as the top priority for policymakers in 2018, outranking issues including the economy, health care costs, social security, and the environment. Polls in Europe also suggest that terrorism continues to be a source of public concern (Renard 2016). This unease is likely amplified when there are highly publicized attacks (Dinesen and Jæger 2013). Attacks that received a great deal of international publicity in recent years include the terrorist bombings of the Boston Marathon on April 15, 2012 (LaFree and Adamczyk 2017); the Charlie Hebdo shootings in Paris on January 7, 2015 (Połońska-Kimunguyi and Gillespie 2016); the coordinated suicide bombings in Brussels on March 22, 2016 (Lasoen 2017); and the Sri Lankan Easter bombings on April 21, 2019 (Singh 2019).

LaFree and Freilich (2012) pointed out in the previous special issue that research on terrorism is far more international in scope than the criminology literature in general. This is underscored by the 11 papers in this volume which are drawn from countries around the world. While three of the contributions to this special issue are from United States data, three are based on data from Israel, two are based on worldwide data, two are based on multiple countries and one is based on data from Ireland. The articles included in this 
special issue are also eclectic in terms of the subjects examined and the methods applied. Three of the articles are based on various types of spatial analyses (Perry 2019; Hasisi et al. 2019b, Marchment et al. 2019). Three additional articles (Hasisi et al. 2019a, LaFree et al. 2019, Corner and Gill 2019) each employ different methods to deal with issues of recidivism and disengagement. Two of the articles (Varaine 2019; Carson et al. 2019) are macro-level studies using time-series data within a single country. Two articles (Semmelbeck and Besaw 2019; McMillan et al. 2019) examine terrorist networks and connections between terrorism and ordinary crime. And finally, one article (Wolfowicz et al. 2019) is a systematic review and meta-analysis of risk and protective factors for radicalization.

This special issue starts with the review article by Wolfowicz, Litmanovitz, Weisburd and Hasisi who provide a systematic review of risk and protective factors for different outcomes of radicalization. Based on extensive searches in English, German and Dutch, the researchers identified nearly 60 studies containing over 70 individual models. They studied three radicalization outcomes: radical attitudes, intentions and behaviors. They used random effects meta-analysis to produce pooled estimates to quantify the effects of all risk and protective factors for which they were able to identify rigorous empirical data. Then, they created a rank order of effect sizes to identify the relative importance of each factor. Across all three outcomes, the researchers find that the most important protective and risk factors are those associated with social control and self-control theories, specifically factors pertaining to peers, school, parenting, social integration, and attitudes towards norms and values such as legitimacy.

In the next contribution, Hasisi, Carmel, Weisburd, and Wolfowicz examined factors that are known to be relevant for criminal recidivism, including incarceration history and demographic background factors. In order to do this, they used a unique dataset of terrorism offenders from Jerusalem provided by the Israeli Prison Service (IPS), which contained enough cases to conduct advanced statistical analyses on the risk of terrorism-related recidivism. Proportional hazards regressions were used to assess which factors independently contribute to the risk of terrorism-related recidivism for first-time and repeat terrorism offenders. The results indicate that the recidivism rate of terrorism offenders is higher than that for ordinary criminal offenders but follows similar patterns with regard to the effects of sentence length, age and prior offending. However, the number of additional incarcerations for regular criminal offenses decreases the risk of terrorism-related recidivism. Also, the role of marital status differs between terrorism-related and non-terrorism related criminal recidivism.

LaFree, Jiang, and Porter investigate the role of imprisonment on the risk of becoming a violent extremist offender. In this contribution, data were used from the PIRUS study (Profiles of Individual Radicalization in the United States) in which information was gathered for a sample of 675 adults that were arrested or convicted of extremist offenses or had strong connections to a terrorist organization. These individuals were categorized in three groups: extremist offenders who spent time in prison and radicalized there, extremist offenders who spent time in prison but were not radicalized there, and extremist offenders who had not spent time in prison prior to their recognized acts of illegal political extremism. The groups were compared and to increase confidence in the results, a set of methodological procedures was used that approximate a fully blocked experimental design, including several robustness tests. This results in consistent evidence that political extremists who have spent time in prison and were radicalized there are more likely to engage in violent political extremism post prison in comparison to the other groups. This means that previous criminological literature showing that prisons play a major role in the identity and behavior of individuals after their release is also relevant for terrorism research. 
In an innovative design, Corner and Gill analyze qualitative autobiographical data using sequence analysis to investigate psychological distress before, during and post engagement in terrorist groups. Their data set comprised 97 autobiographies by 91 individuals, representing a range of group ideologies. Analyzing the chronology of events using proximity coefficients, during and post engagement, their results reveal the correlates of terrorist involvement, with autobiographies discussing eventual burnout, and physiological and psychological distress. Reasons for distress varied greatly, from loneliness and torture, to death of a family member to loss of belief in ideology. Not all individuals expressed psychological distress, however, but those who did reported a wide range of stressors, which may impact psychopathology. Two other important findings stand out. First, that it is not the experience of negative events per se that impacts on psychopathology, but the actor's interpretation of these events, stressing heterogeneity within the group studied. Second, psychological distress during terrorist involvement may have long-lasting consequences. As the authors state, de-radicalization and disengagement programs may need to be designed such that they take this long window into account.

Semmelbeck and Besaw attempt to predict what terrorist groups engage in organized crime using the random forest method. Using a set of organizational and environmental variables on a sample of 183 unique terrorist groups using data from the RAND Database of Worldwide Terrorism Incidents (RDWTI), their study arrives at a number of substantive and methodological conclusions. First, their analyses show that it is the characteristics of the terrorist organizations themselves rather than environmental factors that predict their involvement in organized crime. Even though the authors state that their analyses are not designed to identify causal relations, the findings are noteworthy as such organizational characteristics may easily serve as a warning flag (though the authors caution as to the validity of organizational characteristics that may be shielded from scrutiny by these organizations themselves). Second, their analyses highlight how models that incorporate linear associations only, may miss out on the non-linear pathways in which groups end up engaging in organized crime. Important future questions focus on the temporal aspects of when groups adopt or discard engagement opportunities.

McMillan, Felmlee, and Braines investigate how the structure of terrorist networks develop over time, in different phases of their formation and activities. The central idea is that these changes are guided by balancing the needs for efficiency and security in different periods around an attack. The authors used information about individual terrorists and their mutual social relationships from the John Jay and ARTIS Transnational Terrorism database that included links between offenders connected to eleven prominent Jihadi attacks and bombings from the last three decades (e.g., the 2002 Bali bombings). These data were analyzed using a variety of descriptive network measures and Separable Temporal Exponential Random Graph Models (STERGMs). The results indicate that in the period before violent incidents, networks become increasingly well-connected and organized around key actors. These kinds of analyses can help counterterrorism efforts by suggesting which actors in networks are the most influential targets.

Perry points out that most of the prior literature examining the geo-spatial distribution of terrorist attacks has focused on macro-level analyses such as countries and regions while few studies have examined the micro-level distribution of attacks. He argues that this contrasts with studies of ordinary crime, where there is a large body of research on crime in micro-level "hot spots." To bring the advantages of microlevel spatial analysis to the study of terrorism, Perry relies on a database that includes all known terror attacks in the city of Jerusalem between 2000 and 2017. The database includes the exact geographic location of attacks involving explosives, shootings, 
stabbings, attacks with a deadly weapon, and attacks using vehicles. Perry's analysis shows that there is a high frequency of terror attacks concentrated in specific hot spots and these hot spots are relatively stable over time. He points out that these results suggest the need for specialized counterterrorism responses equivalent to the "hot spots policing" strategies which inform ordinary police work.

The paper by Hasisi, Perry, Ilan and Wolfowicz analyzed vehicular attacks in Israel from a micro-place perspective. This paper differs from the other terrorism and place papers in this issue in that its focus is a specific type of terror attack, vehicular attacks. The study compares the relative degree of concentration between Jerusalem and the West Bank, two distinct but neighboring areas. Additionally, the study analyzes the concentration of the travel routes of attackers. Addressing some key issues raised in the criminology literature concerning assessing relative concentration, the study then compares the relative concentrations of the travel routes with the attack sites. The study also finds evidence of a distance-decay pattern, in line with what has been found with respect to other types of ordinary crime.

Marchment, Gill and Morrison seek to identify the risk factors for bombings and bomb hoaxes committed by Violent Dissident Republicans in Belfast, Northern Ireland. They apply risk terrain modelling to each type of incident to identify characteristics of areas that face significant risk. Based on the analysis they conclude that high risk areas for bombings are associated with previous protests and riots, spatial characteristics, punishment attacks and areas dense with pubs and bars. By comparison, bomb hoaxes are associated with punishment attacks, police stations and areas of the city that are dense with shops. Based on the observed differences between bombings and bomb hoaxes, the researchers conclude that perpetrators choose targets that are relevant to their ideology or that have a greater chance of success. More generally, their results suggest that offenders assess risk and select targets rationally based on these assessments. The authors conclude that risk terrain modeling is a useful tool for guiding more narrowly focused responses to terrorist attacks.

The central motivation for Varaine's contribution to the special issue is that the widespread assumption that economic deprivation has little effect on terrorist activities misses the possibility that this differs between different types of extremism. The author hypothesizes that collective deprivation will affect right and left extremist perpetrators differently: the far-right will mobilize more under times of collective deprivation while the farleft will mobilize more under times of collective economic improvement. Using data from the Profiles of Individual Radicalization (PIRUS) database, the author examines nearly 1300 domestic terrorists in the United States from 1948 to 2016. Using hierarchical logistic regression, the author confirms that the far-right mobilizes more often during periods of long-term economic deprivation, while the far-left mobilizes more under improving economic conditions. At the same time, he shows that Islamist terrorism is unaffected by measures of collective deprivation. Varaine's study challenges the view that economic conditions have no role in triggering terrorist mobilization.

Carson, Dugan and Yang's article focuses on the radical eco-movement. Combining data on U.S. federal government actions and 1068 illegal incidents sourced from the EcoIncidents Database (which includes incidents committed in the name of the environment and/or animal rights), the authors use rational choice theory to investigate whether U.S. federal government actions (such as arrests of activists or governmental actions harmful or beneficial to the environment) impact the behavior of actors within the radical eco-movement. Using Granger causality and autoregressive Poisson analyses, the authors do find that federal government action indeed influences this behavior. When costs increase, eco-incidents decline-although severity of punishment has a null effect. Environment-threatening 
actions by the government are associated with increased incidents, but environment-protecting governmental action was not associated with decreased incidents.

In sum, the eleven articles in this issue demonstrate that criminology and terrorism research continue to be a fruitful combination. The research contributions included here are full of conceptual (recidivism, imprisonment effects, disengagement, hot spots) and methodological (meta-analysis, network analysis, micro-spatial analysis, random forests) references to criminology. These may further advance the quality of terrorism research. The increased application of cutting-edge methods commonly used in criminology, like many of those demonstrated in this issue, will improve the quality of terrorism research. And the application of criminological frameworks may offer fresh perspectives that will help us better understand terrorism and its continuing impact on countries around the world. At the same time, as research on terrorism and violent extremism matures, it increasingly provides insights that may be usefully applied to more common areas of mainstream criminology. The articles included in this special issue also underscore the extent to which terrorism research, compared to the study of more ordinary types of crime, is international in scope, which may also inspire criminological research to take a more globalized perspective, and may encourage criminological researchers from more countries, and hopefully especially countries where terrorism and extremism have disrupted communities, to join and enrich the research endeavour. All in all, we hope that this special issue inspires the reader to also contribute to this interesting and still expanding field with empirically robust, theory-informed and analytically cutting-edge research.

\section{References}

Bialik K (2018) State of the Union 2018: Americans' views on key issues facing the nation. Pew Research Center, Jan 29

Carson JV, Dugan L, Yang SM (2019) A comprehensive application of rational choice theory: how costs imposed by, and benefits derived from, the U.S. federal government affect incidents perpetrated by the radical eco-movement. J Quant Criminol. https://doi.org/10.1007/s10940-019-09427-8

Corner E, Gill P (2019) Psychological distress, terrorist involvement and disengagement from terrorism: a sequence analysis approach. J Quant Criminol. https://doi.org/10.1007/s10940-019-09420-1

Dinesen P, Jæger M (2013) The effect of terror on institutional trust: new evidence from the 3/11 Madrid terrorist attack. Polit Psychol 34(6):917-926

Hasisi B, Carmel T, Weisburd D, Wolfowicz M (2019a) Crime and terror: examining criminal risk factors for terrorist recidivism. J Quant Criminol. https://doi.org/10.1007/s10940-019-09415-y

Hasisi B, Perry S, Ilan Y, Wolfowicz M (2019b) Concentrated and close to home: the spatial clustering and distance decay of lone terrorist vehicular attacks. J Quant Criminol. https://doi.org/10.1007/s1094 0-019-09414-Z

LaFree G (2019) Will terrorism continue to decline in 2019? The conversation. https://theconversation.com/ will-terrorism-continue-to-decline-in-2019-104466. Downloaded Aug 82020

LaFree G, Adamczyk A (2017) The impact of the Boston marathon bombings on public willingness to cooperate with police. Justice Q 34(3):459-490

LaFree G, Dugan L (2016) Evolution of global terrorism: the growing lethality of attacks. In: Backer D, Bhavnani R, Huth PK (eds) Peace and conflict: 2016. Routledge, New York, pp 68-79

LaFree G, Freilich J (2012) Editor's introduction: quantitative approaches to the study of terrorism. J Quant Criminol 28:1-5

LaFree G, Jiang B, Porter LC (2019) Prison and violent political extremism in the United States. J Quant Criminol. https://doi.org/10.1007/s10940-019-09412-1

Lasoen K (2017) Indications and warning in Belgium: Brussels is not Delphi. J Strateg Stud 40(7):927-962

Marchment Z, Gill P, Morrison J (2019) Risk factors for violent dissident republican incidents in belfast: a comparison of bombings and bomb hoaxes. J Quant Criminol. https://doi.org/10.1007/s10940-01909413-0 
McMillan C, Felmlee D, Braines D (2019) Dynamic patterns of terrorist networks: efficiency and security in the evolution of eleven islamic extremist attack networks. J Quant Criminol. https://doi.org/10.1007/ s10940-019-09426-9

Miller E (2020) Global terrorism overview: terrorism in 2019. https://www.start.umd.edu/pubs/START _GTD_GlobalTerrorismOverview2019_July2020.pdf. Downloaded on Aug 82020

Perry S (2019) The application of the "Law of Crime Concentration" to terrorism: the Jerusalem case study. J Quant Criminol. https://doi.org/10.1007/s10940-019-09411-2

Połońska-Kimunguyi E, Gillespie M (2016) Terrorism discourse on French international broadcasting: France 24 and the case of Charlie Hebdo attacks in Paris. Eur J Commun 31(5):568-583

PRIME (2015) Plug and produce intelligent multi agent environment based on standard technology. https:// cordis.europa.eu/project/id/314762. Downloaded Aug 132020

PROTON (2020) https://www.projectproton.eu/about/. Downloaded Aug 82020

Renard T (2016) Fear not: a critical perspective on the terrorist threat in Europe. Egmont Security Policy Brief No. 77 Sept

Schuurman B (2020) Research on terrorism, 2007-2016: a review of data, methods, and authorship. Terror Polit Violence 32(5):1011-1026

Semmelbeck J, Besaw C (2019) Exploring the determinants of crime-terror cooperation using machine learning. J Quant Criminol. https://doi.org/10.1007/s10940-019-09421-0

Singh S (2019) Easter attacks in Sri Lanka. Econ Polit Wkly 54(20):12-14

Varaine S (2019) Revisiting the economics and terrorism nexus: collective deprivation, ideology and domestic radicalization in the US (1948-2016). J Quant Criminol. https://doi.org/10.1007/s10940-01909422-z

Wolfowicz M, Litmanovitz Y, Weisburd D, Hasisi B (2019) A field-wide systematic review and meta-analysis of putative risk and protective factors for radicalization outcomes. J Quant Criminol. https://doi. org/10.1007/s10940-019-09439-4

Publisher's Note Springer Nature remains neutral with regard to jurisdictional claims in published maps and institutional affiliations. 